\title{
PHÂN BỐ HÀM LƯợNG CHLOROPHYLL TRUNG BÌNH THÁNG VÙNG BIỂN ĐÔNG TƯ THÁNG 8/2011 ĐẾN 7/2012
}

\author{
Vũ Văn Tác \\ Viện Hải Dương Học-Viện Hàn lâm Khoa học và Công nghệ Việt Nam \\ E-mail: quiet_seavn@yahoo.com
}

Ngày nhận bài: 25-7-2013

\begin{abstract}
TÓM TÄT: Bài báo trình bày tập sơ đồ mô tả phân bố hàm luợng chlorophyll trung bình tháng ở tầng mặt vùng Biển Đông, tù̀ tháng 8/2011 đến tháng 7/2012. Mỗi sơ đồ là một bức tranh sinh động mô tả hàm luợng chlorophyll thông qua các dải màu sắc nét, giúp cho độc giả có một cái nhìn trục quan về phân bố hàm luợng chlorophyll ở những điểm, nhũng vùng khác nhau trên toàn vùng Biển Đông. Qua đó, có thể thấy nguồn số liệu chlorophyll được giải đoán tù ảnh viến thám chụp tù̀ vệ tinh Aqua của Cuc quản trị Hàng không và Vũ tru Hoa Kỳ(US NASA) là đáng tin cậy và có thể sử dụng trong việc nghiên cứu sức sản xuất sơ cấp cũng nhu giám sát chất luợng môi truờng nước.
\end{abstract}

Tù̀ khóa: Bản đồ, chlorophyll, Biển Đông.

\section{GIỚI THIỆU}

Hiện nay, yếu tố chlorophyll được ứng dụng rộng rãi và phổ biến trong việc nghiên cứu sức sản xuất sơ cấp cũng như giám sát chất lượng môi trường nước. Tuy nhiên, nguồn số liệu chlorophyll trong Cơ sở dữ liệu biển Quốc gia $(C S D L V N O D)$ rất ít, chỉ có 1.800 trạm khảo sát với 4.359 số số liệu đo rải rác trong khoảng thời gian 40 năm (trong vùng Biển Đông, từ 1961-2002). Điều này có nghĩa là CSDL VNOD hoàn toàn không có số liệu chlorophyll trong hơn 10 năm trở lại đây.

Trong khoảng 10 năm trở lại đây, Viện Hải dương học và khá nhiều cơ quan nghiền cứu biển trong nước thực hiện nhiều dự án liên quan đến môi trường biển, trong đó có đo đạc yếu tố chlorophyll như đề tài $K C \cdot 09.05 / 06-1$, KC.09.21/06-10 của Liên đoàn Địa chất Biển, KC.09.03/06-10 của Viện Hải dương học, chương trình hợp tác hợp tác "Khảo sát Nghiên cứu khoa học Biển phối hợp Việt Nam - Philippin trên Biển Đông" (JOMSRE-SCS), chương trình hợp tác nghiên cứu biển Việt Nam - Đức về Tương tác đất liền - đại dương trong vùng biển ven bờ Nam Việt Nam ... Tuy nhiên, việc thu thập số liệu từ những đề tài này để cập nhật cho CSDL VNOD gặp rất nhiều khó khăn liên quan đến bản quyền và sở hữu số liệu.

Ngày nay, với tiến bộ của khoa học kỹ thuật, việc ứng dụng công nghệ viễn thám đã xác định được hàm lượng chlorophyll thông qua các bức ảnh chụp bề mặt nước dựa trên nguyên lý thu nhận năng lượng phản xạ, bức xạ từ đối tượng nghiên cứu.

Ở Việt Nam, do chưa có điệu kiện phóng vệ tinh nên đa số những bức ảnh do vệ tinh chụp đều phải mua từ nước ngoài để phục vụ nghiên cứu cho từng ngành cụ thể (chúng ta có 2 vệ tinh là vinasat-I và vinasat-II, nhưng chì là vệ tinh viễn thông). hiện nay trong không gian vũ trụ đang tồn tại hàng trăm vệ tinh khác nhau nhiều quốc gia. Một trong những cơ quan hàng đầu thế giới về công nghệ viễn thám là US NASA (Cục quản trị Hàng không và Vũ trụ Hoa Kỳ). Các ảnh viễn thám do cơ quan này chụp, xử lý được và công bố, chia sẻ miễn phí trên website (http://oceancolor.gsfc.nasa.gov/). 
Để lấp khoảng trống dữ liệu chlorophyll trong CSDL VNOD, năm 2012 phòng Dữ liệu biển, Viện Hải dương học đã thực hiện đề tài nghiên cứu khoa học cấp cơ sở CS2012.11 để "Khai thác nguồn số liệu chlorophyll vùng Biển Đông qua ảnh MODIS từ website của US NASA". Kết quả, đề tài đã khai thác được một khối lượng dữ liệu chlorophyll rất lớn và có độ tin cậy cao từ ảnh MODIS-Level 3 (ảnh đã được xử lý) của US NASA. Hơn 25 triệu giá trị trung bình tháng của yếu tố chlorophyll được giải đoán từ ảnh viễn thám trong thời gian 10 năm (7/2002-7/2012) là nguồn số liệu rất có giá trị cho việc giám sát chất lượng môi trường nước cũng như nghiên cứu sức sản xuất sơ cấp ở vùng Biển Đông. Nguồn số liệu khai thác nói trên được tập hợp, lưu trữ và quản lý trong cơ sở dữ liệu riêng (Hệ quản trị cơ sở dữ liệu Microsoft Access), vì vậy rất thuận tiện cho việc khai thác và sử dụng (ngoài nguổn ảnh MODIS, US NASA còn có ảnh SEA-WiFS nhưng nguồn ảnh này không miễn phí).

Bài báo này sử dụng nguồn số liệu chlorophyll mà đề tài CS2012.11 đã khai thác để xây dựng tập sơ đồ mô tả phân bố hàm lượng chlorophyll trung bình tháng ở tầng mặt vùng Biển Đông, từ tháng $8 / 2011$ đến tháng 7/2012. Mỗi sơ đồ là một bức tranh sinh động mô tả hàm lượng chlorophyll thông qua các dải màu sắc nét, giúp cho độc giả có một cái nhìn trực quan về phân bố hàm lượng chlorophyll ở những điểm, những vùng khác nhau trên toàn vùng Biển Đông. Qua kêt quả này, có thể thấy được nguồn số liệu chlorophyll được giải đoán từ ảnh viễn thám chụp từ vệ tinh Aqua của US NASA là đáng tin cậy và có thể sử dụng trong việc nghiên cứu sức sản xuất sơ cấp cũng như giám sát chất lượng môi trường nước vùng Biển Đông nói riêng và trên thế giới nói chung. Đặc biệt, nguồn số liệu này là hoàn toàn miễn phí.

\section{PHAM VI VÀ PHƯƠNG PHÁP NGHIÊN CứU}

\section{Phạm vi khai thác số liệu}

Phạm vi mô tả của các ảnh MODIS giải đoán chlorophyll ở cấp độ 3 của US NASA là toàn cầu. Tuy nhiên, phạm vi quản lý số liệu trong cơ sở dữ liệu VNOD chỉ giới hạn trong vùng Biển Đông và lân cận, được giới hạn từ kinh độ $99^{\circ} \mathrm{E}$ đến $125^{\circ} \mathrm{E}$ và vĩ độ từ $5^{\circ} \mathrm{S}$ đến $25^{0} \mathrm{~N}$. Vì vậy, việc khai thác số liệu chlorophyll cũng giới hạn trong phạm vị trên (hình 1).

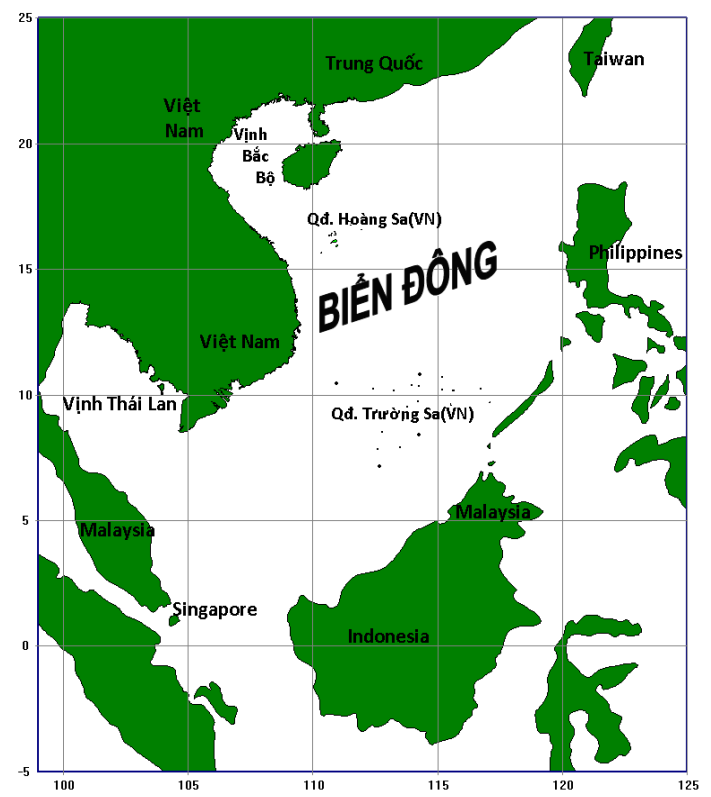

Hình 1. Phạm vi quản lý số liệu trong VNOD

\section{Phương pháp nghiên cứu}

Các phần mềm được sử dụng để xây dựng bản đồ

Sử dụng ngôn ngữ Visual Basic 6.0 và trình $\mathrm{ADO}$ để lọc, phân tích và xử lý số liệu.

Sử dụng phần mềm Oean Data View 4 để xây dựng các sơ đồ màu.

Sử dụng phần mềm SAGA để xây dựng các biểu đồ mô tả trực quan chuỗi số liệu chlorophyll.

Kiểm tra chất luợng số liệu chlorophyll trong các file ảnh

Việc đánh giá chất lượng nguồn số liệu chlorophyll thu được từ các ảnh viễn thám là một việc không đơn giản. Kết quả giải đoán ảnh viển thám phụ thuộc rất nhiều yểu tố như thời tiết, thời gian và thiết bị chụp cũng như các thuật toán sử dụng trong việc giải đoán. Trong quá trình xây dựng tập bản đồ này, chúng tôi dựa trên những nghiên cứu về chlorophyll trong và ngoài nước để đánh giá sơ bộ chất lượng nguồn số liệu chlorophyll như sau. 
Theo kết quả nghiên cứu của Võ Văn Lành và đồng nghiệp [2], khoảng giới hạn của yếu tố chlorophyll vùng Biển Đông được xác định là $(0,20)$, được xác định dựa trên 1.894 trạm với 3.467 số số liệu, quan trắc trong khoảng thời gian từ 1961-1998.

Tuy nhiên, theo tài liệu cơ sở dữ liệu biển thế giới 2009 [1], thì giới hạn của yếu tố chlorophyll được mô tả như trong bảng 1 .

Bảng 1. Giới hạn của yếu tố chlorophyll $\left(\mathrm{mg} / \mathrm{m}^{3}\right)$ tầng mặt

\begin{tabular}{cccc}
\hline \multicolumn{3}{c}{ Ven bò̀ } & \multicolumn{2}{c}{ Vùng khơi } \\
\hline \multicolumn{4}{c}{ Vùng biển Bắc Thái Bình Dương } \\
Dưới & Trên & Dưới & Trên \\
0 & 50 & 0 & 1,5 \\
& Vùng biển xích đạo Thái Bình Dương & \\
Dưới & Trên & Dưới & Trên \\
0 & 50 & 0 & 1 \\
\hline
\end{tabular}

Ghi chú: Theo cách phân chia của NODC, vùng Biển Đông gần nhu nằm trọn trong vùng biển Bắc Thái Bình Dưong. Tuy nhiên, có một phần thuộc về vùng biển xích đạo Thái Bình Dưong.

Để đánh giá sơ bộ chất lượng nguồn số liệu chlorophyll trên, cả 2 khoảng giới hạn trên $\{(0$, $20)$ và $(0,50)\}$ đã được lần lượt sử dụng để kiểm tra. Kết quả kiểm tra được mô tả trong bảng 2 .

Bảng 2. Kết quả kiểm tra chất lượng nguồn số liệu chlorophyll $\left(\mathrm{mg} / \mathrm{m}^{3}\right)$

\begin{tabular}{ccccc}
\hline $\begin{array}{c}\text { Khoảng giới } \\
\text { hạn sử dụng } \\
\text { kiểm tra }\end{array}$ & $\begin{array}{c}\text { Tổng số số } \\
\text { liệu kiểm } \\
\text { tra }\end{array}$ & $\begin{array}{c}\text { Số số liệu nằm } \\
\text { ngoài khoảng } \\
\text { giơơi hạn }\end{array}$ & $\begin{array}{c}\text { Tỷ lệ } \\
\%\end{array}$ \\
\cline { 1 - 1 } \cline { 5 - 6 }$(0,20)$ & 25.401 .154 & & 12.330 & 0,05 \\
$(0,50)$ & 25.401 .154 & 1.080 & 0,04 \\
\hline
\end{tabular}

Ghi chú: - Giá trị nhỏ nhất trong tập số liệu chlorophyll là: 0,002021( $\left.\mathrm{mg} / \mathrm{m}^{3}\right)$

chlorophyll là: 99,93376( $\left.\mathrm{mg} / \mathrm{m}^{3}\right)$

- Giá trị lớn nhất trong tập số liệu

Theo kết quả kiểm tra chất lượng nguồn số liệu chlorophyll (bảng 2), 99,95\% số liệu nằm trong khoảng $(0,20)$ và $99,996 \%$ số liệu nằm trong khoảng $(0,50)$. Điều này có nghĩa là những giá trị chlorophyll lớn hơn $20 \mathrm{mg} / \mathrm{m}^{3}$ là rất hiếm và các số liệu chlorophyll giải đoán từ ảnh viễn thám là hợp lý và đáng tin cậy. Vì vậy, khoảng dữ liệu $(0,20)$ đã được chọn để lọc dữ liệu cho việc xây dựng tập bản đồ này.
So sánh tập số liệu chlorophyll đã khai thác với tập số liệu chlorophyll quan trắc thực tế trong CSDL VNOD

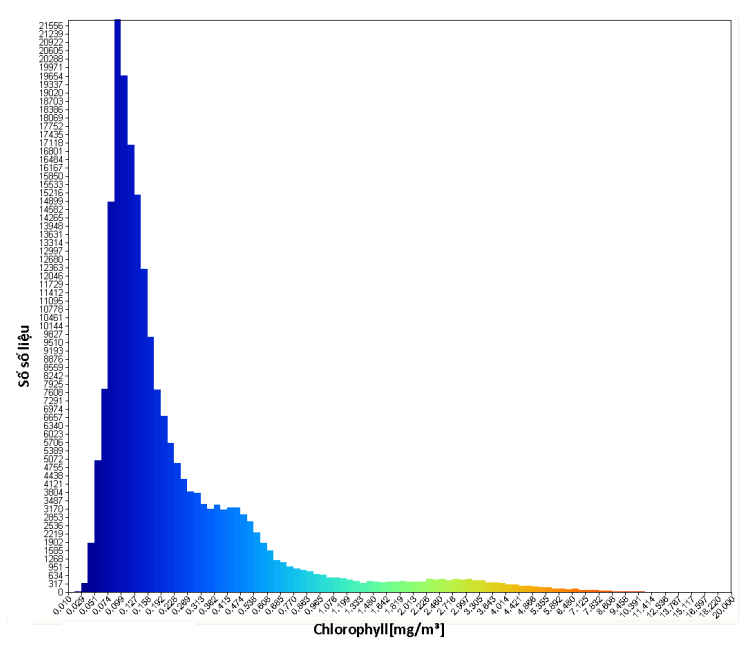

Hình 2. Biểu đồ phân bố số liệu chlorophyll $\left(\mathrm{mg} / \mathrm{m}^{3}\right)$ theo các khoảng giá trị (Nguồn tù ảnh MODIS trung bình của tháng 7/2012 (gồm 216.030 giá tri)

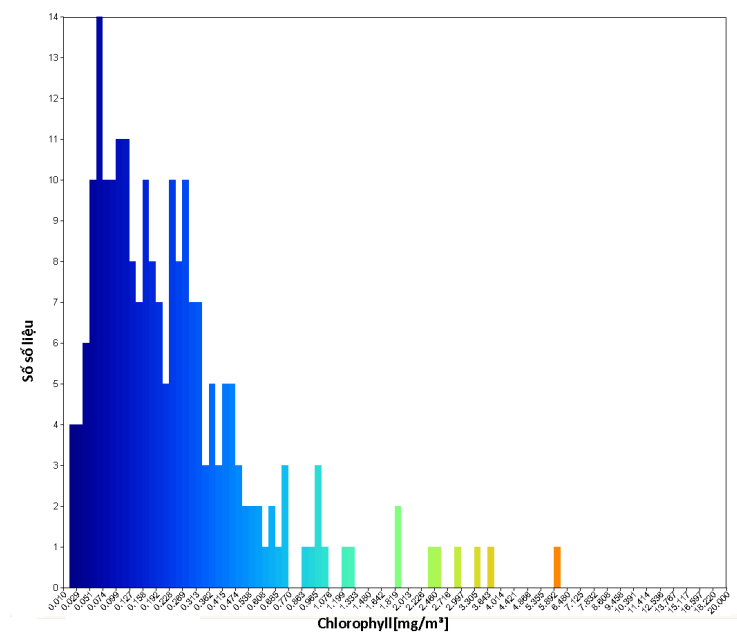

Hình 3. Biểu đồ phân bố số số liệu chlorophyll $\left(\mathrm{mg} / \mathrm{m}^{3}\right)$ theo các khoảng giá trị. (Nguồn tù̀ CSDL VNOD (gồm 1594 giá trị, quan trắc trong 1961 - 2002)

Để so sánh một cách trực quan giữa tập số liệu chlorophyll đã khai thác với tập số liệu chlorophyll quan trắc thực tế trong CSDL VNOD, chúng tôi xây dựng 2 biểu đồ mô tả khoảng đặc trưng của chuỗi số liệu chlorophyll tương ứng như mô tả trong hình 2 và hình 3 . 
Đối với tập số liệu chlorophyll trong CSDL VNOD, số liệu đo ở tầng mặt bao gồm 1.594 trạm, quan trắc trong khoảng thời gian từ năm 1961 đến 2002. Đối với tập số liệu chlorophyll khai thác từ ảnh MODIS, toàn bộ số liệu trung bình của tháng 7/2012 được chọn để xây dựng biểu đồ. Đây là file số liệu gần y nhất mà đề tài CS2012.11 khai thác được.

Dựa vào 2 biểu đồ như mô tả trong hình 2 và hình 3 , chúng ta có thể dễ dàng nhận thấy những nét tương đồng về khoảng đặc trưng của giá trị chlorophyll: Phần lớn các giá trị chlorophyll tập trung trong khoảng $(0,03-1,5)$. Trong khoảng $(1,6-10)$ giá trị chlorophyll rât ít và giá trị chlorophyll lớn hơn 10 là rất hiếm. Mặc dù việc so sánh 2 tập dữ liệu chlorophyll ở 2 thời điểm cách nhau hơn 10 năm là khập khiễng, vì chlorophyll phản ánh chất lượng môi trường và biến động theo thời gian. Tuy nhiên, những biến động này luôn nằm trong một khoảng giới hạn cố định như đã đề cập trong bảng 1 . Chính vì vậy mà sự tương đồng giữa 2 biểu đồ trên một lần nữa phản ánh độ tin câyy của tập số liệu chlorophyll giải đoán từ ảnh MODIS.

\section{KẾT QUẢ NGHIÊN CỨU}

Tập sơ đồ phân bố chlorophyll trung bình tháng

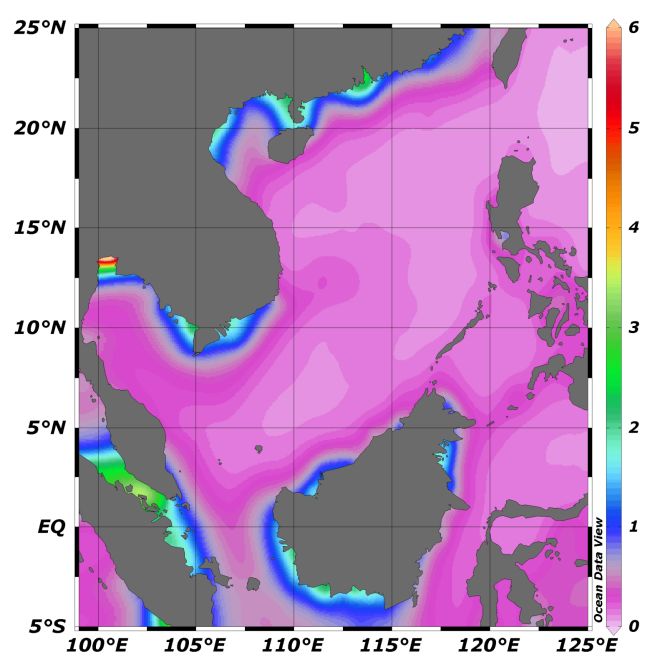

Hình 4. Phân bố chlorophyll $\left(\mathrm{mg} / \mathrm{m}^{3}\right)$ trung bình ở tầng mặt vùng Biển Đông và lân cận: $8 / 2011$

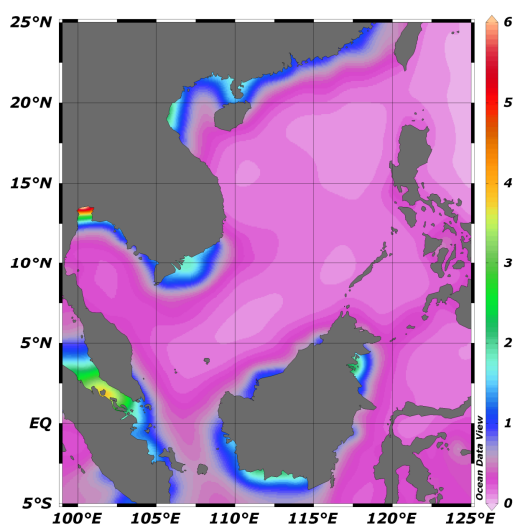

Hình 5. Phân bố chlorophyll trung bình ở tầng mặt vùng Biển Đông và lân cận: 9/2011

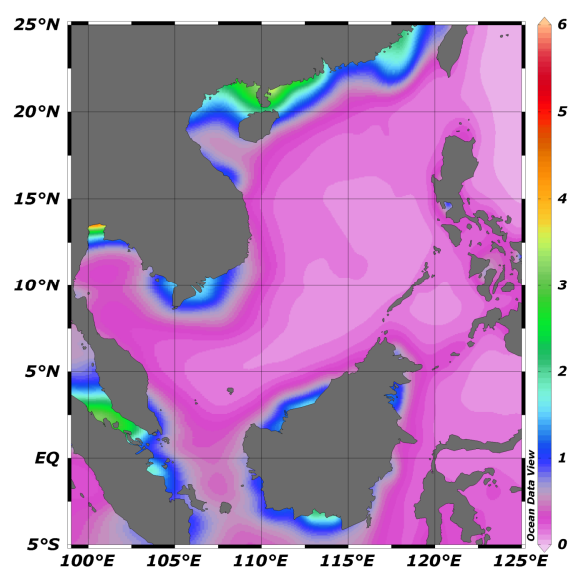

Hình 6. Phân bố chlorophyll trung bình ở tầng mặt vùng Biển Đông và lân cận: 10/2011

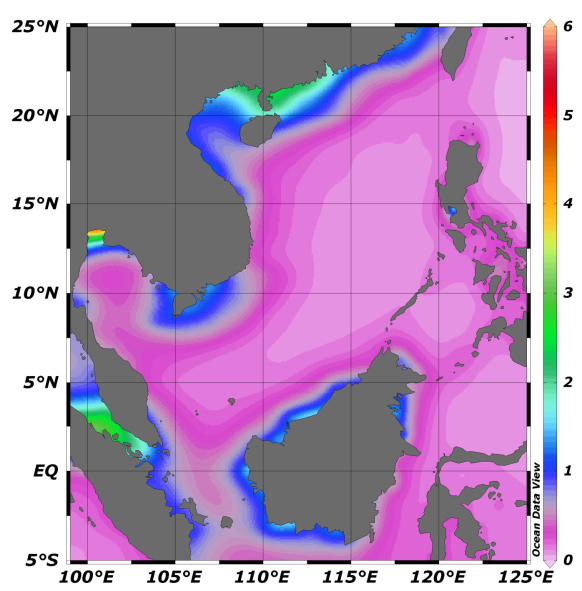

Hình 7. Phân bố chlorophyll trung bình ở tầng mặt vùng Biển Đông: 11/2011 
Phân bố hàm lượng chlorophyll trung bình ...

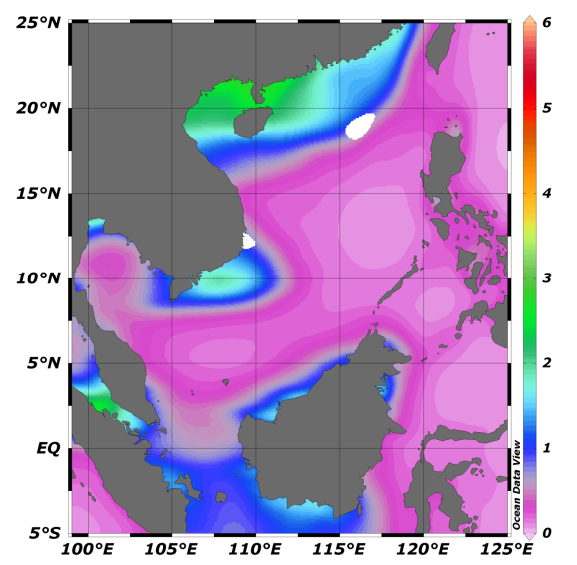

Hình 8. Phân bố chlorophyll trung bình ở tầng mặt vùng Biển Đông và lân cận: 12/2011

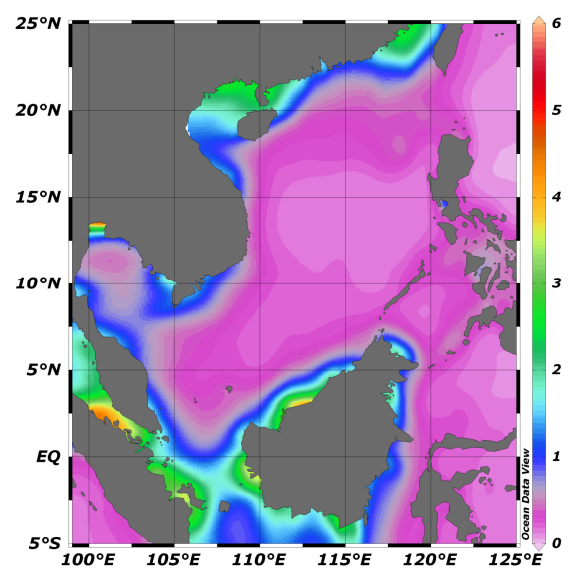

Hình 9. Phân bố chlorophyll trung bình ở tầng mặt vùng Biển Đông và lân cận: 1/2012

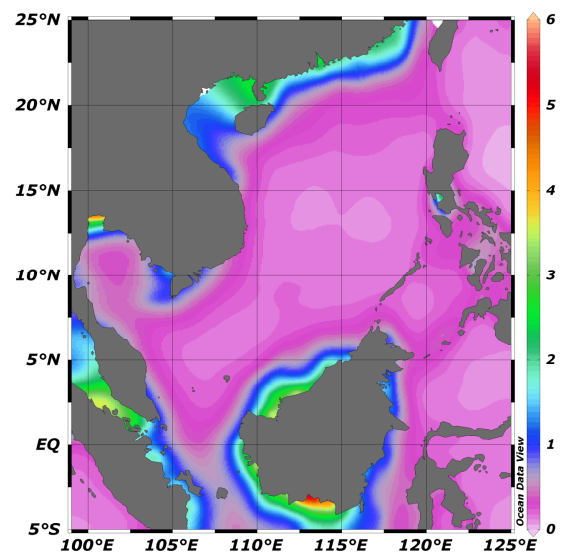

Hình 10. Phân bố chlorophyll trung bình ở tầng mặt vùng Biển Đông và lân cận: 2/2012

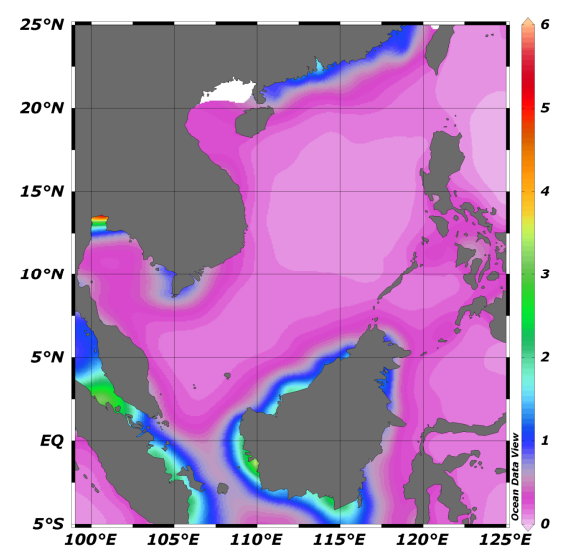

Hình 11. Phân bố chlorophyll trung bình ở tầng mặt vùng Biển Đông và lân cận: 3/2012

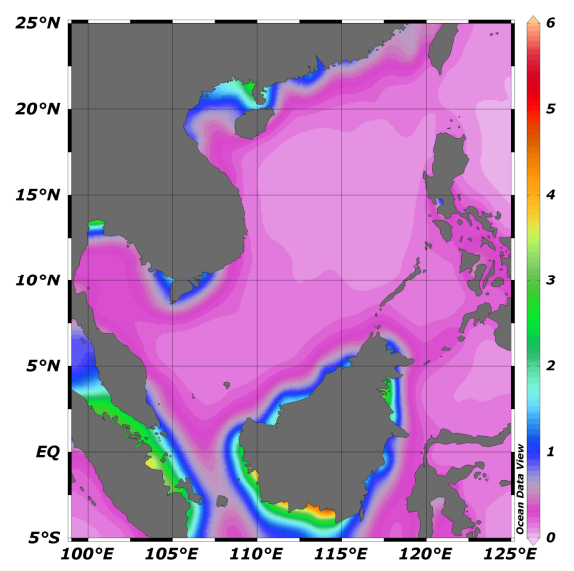

Hình 12. Phân bố chlorophyll trung bình ở tầng mặt vùng Biển Đông và lân cận: 04/2012

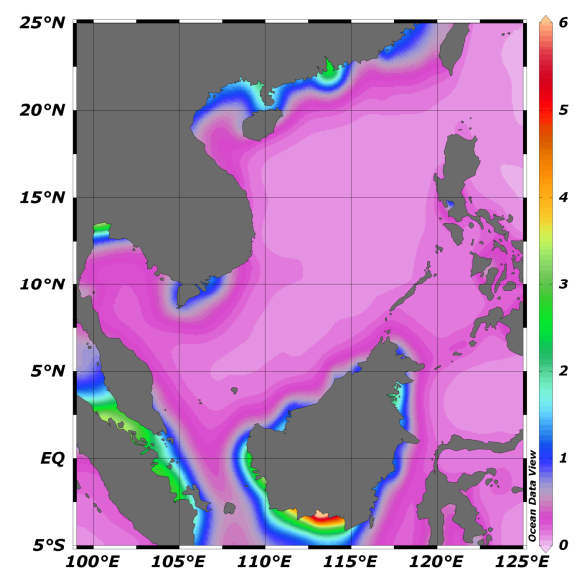

Hình 13. Phân bố chlorophyll trung bình ở tầng mặt vùng Biển Đông và lân cận: 5/2012 


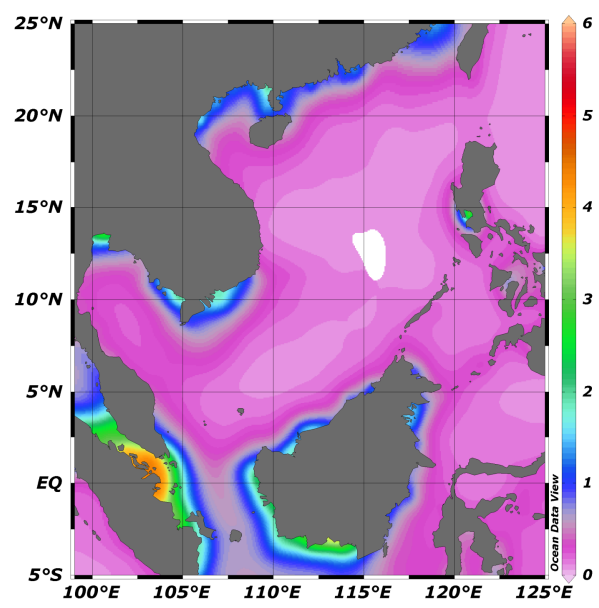

Hình 14. Phân bố chlorophyll trung bình ở tầng mặt vùng Biển Đông và lân cận: 6/2012

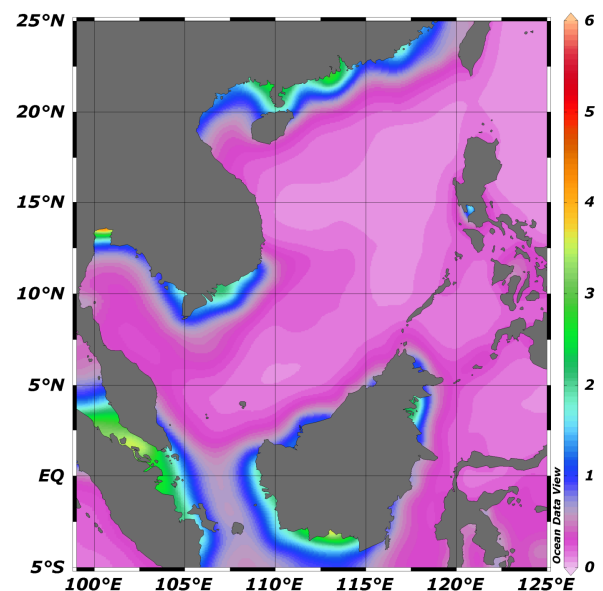

Hình 15. Phân bố chlorophyll trung bình ở tầng mặt vùng Biển Đông và lân cận: 7/2012

Từ hình 4 đến hình 15 là các sơ đồ phân bố mật độ các điểm ảnh và giá trị trung bình tháng của yếu tố chlorophyll ở tầng mặt, tương ứng từ tháng $8 / 2011$ đến tháng $7 / 2012$.

\section{KẾT LUÂNN}

Hiện nay, hàm lượng chlorophyll được ứng dụng phổ biên trong việc giám sát chất lượng môi trường nước cũng như nghiên cứu sức sản xuất sơ cấp. Việc sử dụng ảnh viễn thám để nghiên cứu về phân bố hàm lượng chlorophyll là một hướng mới và rất hiệu quả. Tuy nhiên, kinh phí cho việc mua ảnh viễn thám có chất lượng cao như SPOT5, IKNOS, ASTER v.v. cũng như bản quyền của những phần mền chuyên dụng cho việc giải đoán ảnh viễn thám là rât cao và đỏi hỏi người sử dụng phải đạt một trình độ chuyên môn nhất định. Vì vậy, việc chọn ảnh US MODIS của NASA để khai thác dữ liệu là một hướng nghiên cứu rất thiết thực, chi phí thấp nhưng hiệu quả cao vì nguồn ảnh này hoàn toàn miễn phí và có chất lượng rất đáng tin cậy. Ngoài ra, nguồn ảnh này đã được phòng Dữ liệu biển, Viện Hải dương học chuyển đổi, đồng thời tập hợp và lưu trữ trong một CSDL số, rất thuận tiện trong việc phân tích, xử lý, khai thác và nghiên cứu.

\section{TÀI LIỆU THAM KHẢO}

1. Johnson, D. R., T. P. Boyer, H. E. Garcia, R. A. Locarnini, O. K. Baranova and M. M. Zweng, 2009. World Ocean Database 2009 Documentation. Edited by Sydney Levitus. NODC Internal Report 20, NOAA Printing Office, Silver Spring, MD, 175 pp. Available http://www.nodc.noaa.gov/OC5/WOD09/pr _wod09.html.

2. Võ Văn Lành, Phan Quảng, Vũ Văn Tác, Làu Và Khìn, Ngô Mạnh Tiên, Đặng Ngọc Thanh, 2000. The oceanographic database of the South China Sea and adjacent waters. Collection of Marine Research Works. Science and Technique Publishing House. Vol. 10, 254-259. 
Phân bố hàm lượng chlorophyll trung bình ...

\title{
MONTHLY AVERAGE DISTRIBUTION OF CHLOROPHYLL IN EASTERN SEA FROM AUGUST 2011 TO JULY 2012
}

\author{
Vu Van Tac \\ Institute of Oceanography-VAST
}

\begin{abstract}
This paper presents the schematic maps describing the distribution of the monthly average chlorophyll content at the surface of the Eastern Sea from August 2011 to July 2012. Each schematic map is a vivid picture describing chlorophyll content through a range of sharp colors, giving readers a visual look on the distribution of chlorophyll content at different points and areas around the Eastern Sea. Thereby, the chlorophyll data, which are interpreted from the remote sensing images of Aqua satellite of National Aeronautics and Space Administration (NASA), are reliable and can be used in the study of primary productivity as well as environmental water quality monitoring.
\end{abstract}

Key words: Maps, chlorophyll, Eastern Sea. 